\title{
LINEARIZATION OF DIFFERENTIAL ALGEBRAIC EQUATIONS WITH INTEGRAL TERMS AND THEIR APPLICATION TO THE THERMAL ENERGY MODELLING
}

\author{
E.V. Chistyakova ${ }^{1}$, V.F. Chistyakov ${ }^{1}, A . A$. Levin $^{2}$ \\ ${ }^{1}$ Matrosov Institute for System Dynamics and Control Theory of Siberian Branch \\ of Russian Academy of Sciences, Irkutsk, Russian Federation \\ ${ }^{2}$ Melentiev Energy Systems Institute Siberian Branch of the Russian Academy \\ of Sciences, Irkutsk, Russian Federation \\ E-mails: elena.chistyakova@icc.ru, chist@icc.ru, lirt@mail.ru
}

\begin{abstract}
Modelling of various natural and technical processes often results in systems that comprise ordinary differential equations and algebraic equations This paper studies systems of quasi-linear integral-differential equations with a singular matrix multiplying the higher derivative of the desired vector-function. Such systems can be treated as differential algebraic equations perturbed by the Volterra operators. We obtained solvability conditions for such systems and their initial problems and consider possible ways of linearization for them on the basis of the Newton method. Applications that arise in the area of thermal engineering are discussed and as an example we consider a hydraulic circuit presented as a system comprising an interconnected set of discrete components that transport liquid. Numerical experiments that employed the implicit Euler scheme showed that the mathematical model of the straight-through boiler with a turbine and a regeneration system has a solution and this solution tends to the stationary mode preset by regulators.

Keywords: differential algebraic equations; Fredholm operator; Volterra operator; initial problem; consistency problem; index.
\end{abstract}

\section{Problem Statement and Auxiliary Information}

Modelling of natural and technical processes often yields systems that comprise ordinary differential equations (ODEs) of various order and algebraic equations (cf. [1-6]). Their combination can be written in a form of quasi-linear vector ODEs with a singular matrix multiplying the higher derivative of the desired vector-function

$$
\begin{gathered}
\Lambda_{k}(u) u:=\hat{A}\left(u^{(k-1)}, \cdots, u^{(1)}, u, t, \lambda\right) u^{(k)}+\hat{B}\left(u^{(k-1)}, \cdots, u^{(1)}, u, t, \lambda\right)=0, \\
k=1,2, \cdots
\end{gathered}
$$

where $\hat{A}\left(g_{k-1}, \cdots, g_{1}, g_{0}, t, \lambda\right), \hat{B}\left(g_{k-1}, \cdots, g_{1}, g_{0}, t, \lambda\right)$ are given $(\nu \times n)$-matrix and an $\nu$ dimensional vector-function, correspondingly, $g_{k-1}, \cdots, g_{1}, g_{0} \in \mathbf{R}^{n}, t \in T=[\alpha, \beta] \subset$ $\mathbf{R}^{1}, u \equiv u(t)$ is $n$-dimensional vector-function $u^{(i)}(t)=(d / d t)^{i} u(t), i=1,2, \cdots, u^{(0)}(t)=$ $u(t), \lambda$ is a scalar parameter, and matrix $\hat{A}$ is such that

$$
\operatorname{rank} \hat{A}<\min (n, \nu)
$$

for all values of arguments from the domain. For the case of closed systems $(\nu=n)$, this condition takes the form $\operatorname{det} \hat{A}=0$. Such systems are commonly referred to differential algebraic equations (DAEs). If the process under study has a so-called aftereffect, then 
the system may include integral equations. Therefore, in this work we focus our attention on the systems with Volterra and Fredholm operators

$J_{k}(u) u:=\mathrm{A}\left(u^{(k-1)}, \cdots, u^{(1)}, u, t, \mathcal{V} u, \mathcal{K} u, \lambda\right) u^{(k)}+\mathrm{B}\left(u^{(k-1)}, \cdots, u^{(1)}, u, t, \mathcal{V} u, \mathcal{K} u, \lambda\right)=0$,

where $\mathrm{A}\left(g_{k-1}, \cdots, g_{1}, g_{0}, \gamma_{1}, \gamma_{0}, t, \lambda\right), \mathrm{B}\left(g_{k-1}, \cdots, g_{1}, g_{0}, \gamma_{1}, \gamma_{0}, t, \lambda\right)$ are given $(\nu \times n)$-matrix and an $\nu$-dimensional vector-function, correspondingly, $\gamma_{1}, \gamma_{0}, \in \mathbf{R}^{n}$,

$$
\mathcal{V} u=\int_{\alpha}^{t} K(t, s, u(s)) d s, \mathcal{K} u=\int_{\alpha}^{\beta} K_{1}(t, s, u(s)) d s
$$

are the Volterra and Fredholm operator, $K, K_{1}: T \times T \times \mathbf{R}^{n} \rightarrow \mathbf{R}^{\tilde{n}}$, and matrix $\hat{A}$ is such that

$$
\operatorname{rank} \mathrm{A}<\min (n, \nu)
$$

for all values of arguments from the domain. Linear DAEs (1), (3) for $n=\nu$ have the following form

$$
\Lambda_{k} x:=\sum_{i=0}^{k} A_{i}(t) x^{(i)}(t)=f(t), t \in T
$$

where $A_{i}(t)$ are $(n \times n)$-matrices, $x(t)$ and $f(t)$ are the desired and the given vectorfunctions, correspondingly, $x^{(i)}(t)=(d / d t)^{i} x(t), x^{(0)}(t)=x(t)$,

$$
\left(\Lambda_{k}+\lambda V+\mu \Phi\right) z:=\sum_{i=0}^{k} A_{i}(t) z^{(i)}(t)+\lambda \int_{\alpha}^{t} \mathcal{K}(t, s) z(s) d s+\mu \int_{\alpha}^{\beta} \mathrm{K}(t, s) z(s) d s=f(t)
$$

where $\lambda, \mu$ are scalar parameters (possibly, complex cones), $\mathcal{K}(t, s), \mathrm{K}(t, s)$ are $(n \times n)$ matrices define in $T \times T, z(t)$ is the desired vector-function. As follows we assume that all entries are smooth enough and that the following condition is satisfied

$$
\operatorname{det} A_{k}(t)=0 \forall t \in T \text {. }
$$

DAEs with $k=1$ have been fairly well studied (see the monographs [6-8] and the bibliography listed therein). Any equation (5) can be reduced a first order DAE using a change of variables. However, if $k>1$, DAEs possess a number of interesting properties that disappear after such reduction.

It is assumed that for each system (5), (6), a set of initial data is given

$$
x^{(j)}(\alpha)=a_{j}, z^{(j)}(\alpha)=b_{j},
$$

where $a_{j}, b_{j}$ are the given vectors from $\mathbf{R}^{n}$.

By the solution to systems (5), (6) we understand any $k$-times differentiable on $T$ vector-functions $x(t)$. $z(t)$ that turn the systems under study into identity on $T$. If these vector-functions are solutions and satisfy (8), then they are solutions to the corresponding initial problems.

At present, there are available only a few works addressing higher order DAEs (cf. [911]). To study (5), we will employ the tools and results that had been previously developed for the first order DAEs. 
For the sake of simplicity, the dependence on $t$ sometimes will be omitted, if does not cause misunderstanding. Inclusions $V(t) \in \mathbf{C}^{i}(T), i \geq 1$, where $V(t)$ is a matrix or a vector-function, mean that all its elements are differentiable on $T$ up to the order $i$. The continuity will be denoted as $V(t) \in \mathbf{C}(T)$; symbol $\mathbf{C}^{A}(T)$ stands for the space of real analytical matrices. Below, we will also employ denotation $\mathbf{r}[V(t)]=\max \{\operatorname{rank} V(t), t \in$ $T\}$.

Here we also use the norms of $q$-dimensional vector $\zeta=\left(\zeta_{1}, \zeta_{2}, \ldots, \zeta_{q}\right)^{\top} \in \mathbf{R}^{q}$, and vector-function $\zeta(t)=\left(\zeta_{1}(t), \zeta_{2}(t), \ldots, \zeta_{q}(t)\right)^{\top}, t \in T$, which are found by the following rules

$\|\zeta\|_{E}^{2}=\sum_{j=1}^{q} \zeta_{j}^{2},\|\zeta\|_{I}=\max _{j \in[1, \cdots, q]}\left|\zeta_{j}\right|,\|\zeta(t)\|_{L_{2}(T)}^{2}=\int_{\alpha}^{\beta}\|\zeta(s)\|_{E}^{2} d s,\|\zeta(t)\|_{\mathbf{C}(T)}=\max _{t \in T}\|\zeta(t)\|_{I}$

where $\top$ stands for transposition.

Definition 1. [7] The $(n \times m)$-matrix $M^{+}(t)$ is said to be the pseudoinverse to $(m \times n)$ matrix $M(t)$ if $\forall t \in T$

$$
\begin{gathered}
M(t) M^{+}(t) M(t)=M(t), M^{+}(t) M(t) M^{+}(t)=M^{+}(t), \\
\left(M^{+}(t) M(t)\right)^{\top}=M^{+}(t) M(t),\left(M(t) M^{+}(t)\right)^{\top}=M(t) M^{+}(t) .
\end{gathered}
$$

The pseudoinverse matrix is defined for any $t \in T$ and for any $(m \times n)$-matrix $M(t)$ and is unique. If $M(t)$ is square and nonsigular, then $M^{-1}(t)=M^{+}(t)$. Accodring to [7], there exists $M^{+}(t) \in \mathbf{C}^{q}(T)$, if $M \in \mathbf{C}^{q}(T)$ and $\operatorname{rank} M(t)=r=$ const $\forall t \in T$. If rank $M(t) \neq$ const, $t \in T$, then at least one element of $M^{+}(t)$ has a second kind discontinuity on $T$.

Below we will use the following operators

$$
\mathrm{d}_{i}[M]=\left(\begin{array}{c}
M \\
(d / d t) M \\
\cdots \\
(d / d t)^{i} M
\end{array}\right), \mathcal{M}_{i}[M]=\left(\begin{array}{cccc}
C_{0}^{0} M & 0 & \cdots & 0 \\
C_{1}^{0} M^{(1)} & C_{1}^{1} M & \cdots & 0 \\
\vdots & \vdots & \ddots & \vdots \\
C_{i}^{0} M^{(i)} & C_{i}^{1} M^{(i-1)} & \cdots & C_{i}^{i} M
\end{array}\right)
$$

where $M \equiv M(t)$ is some matrix from $\mathbf{C}^{i}(T), C_{i}^{j}=j !(i-j) ! / i$ ! are the binomial coefficients. The operators are related by formula

$$
\mathcal{M}_{i}[M(t) F(t)]=\mathcal{M}_{i}[M(t)] \mathrm{d}_{i}[F(t)],
$$

where $F(t)$ is some matrix of the appropriate size from $\mathbf{C}^{i}(T)$. Formula (10) follows from the Leibniz general rule.

\section{Properties of Linear Systems}

In this section we modify concepts that were introduced earlier in [10]. We single out a class of DAEs, which solution properties are very much similar to those of normal form ODEs. 
Definition 2. Equation (5) has a Cauchy type solution if it is solvable for any $f(t) \in$ $\mathrm{C}^{k n}(T)$ and its solutions can be represented as a linear combination

$$
x(t, c)=X_{d}(t) c+\psi(t)
$$

where $X_{d}(t)$ is an $(n \times d)$-matrix from $\mathbf{C}^{k}(T)$, with the property rank $\mathrm{d}_{k-1}\left[X_{d}(t)\right]=d \forall t \in$ $T, \mathrm{~d}_{k-1}[$.$] is the operator from the formulas (9), c$ is an arbitrary constant vector, $\psi(t)$ is the vector-function with the property $\Lambda_{k} \psi(t)=f(t), t \in T$. Additionally, on any subsegment $\left[\alpha_{0}, \beta_{0}\right] \subseteq T$ there is no solution different to $x(t, c)$.

Solution $x(t)$ that passes through point $x^{(i)}(\gamma)=a_{i}, i=\overline{0, k-1}, \gamma \in T$, is unique if there exists $c$ such that $\mathrm{d}_{k-1}\left[X_{d}(\gamma)\right] c=\bar{a}-\mathrm{d}_{k-1}[\psi(\gamma)]$, where $\bar{a}=\left(\begin{array}{llll}a_{1}^{\top} & a_{2}^{\top} & \ldots & a_{k-1}^{\top}\end{array}\right)^{\top}$. The vector $c$ always exists for normal form ODEs, because

$$
d=n k, \operatorname{det} \mathrm{d}_{k-1}\left[X_{d}(t)\right] \neq 0 \forall t \in T .
$$

Definition 3. If there exists operator $\Omega_{l}=\sum_{j=0}^{l} L_{j}(t)(d / d)^{j}$, where $L_{j}(t)$ are $(n \times n)$ matrices from $\mathbf{C}(T)$, such that $\Omega_{l} \circ \Lambda_{k} y=\sum_{i=0}^{k} \tilde{A}_{i}(t) y^{(i)}(t) \forall y(t) \in \mathbf{C}^{l+k}(T)$, where $\tilde{A}_{i}(t)$ are some $(n \times n)$-matrices from $\mathbf{C}(T), i=\overline{0, q}$, $\operatorname{det} \tilde{A}_{k}(t) \neq 0 \forall t \in T$, then operator $\Omega_{l}$ is said to be the left regularizing operator (LRO) for the system (5). The smallest possible $l$ is said to be the index of the system.

Definition 4. The combination of (5) and its $i$ derivatives $\mathrm{d}_{i}\left[\Lambda_{k} x-f\right]=0, t \in T$, where $\mathrm{d}_{i}[$.$] is the operator defined by (9), is called i$-extended system (5).

Using (10), $i$-extended system can be written as

$$
D_{i}[\mathbf{A}(t)] \mathrm{d}_{i+k}[x]=\sum_{j=0}^{k}\left(O_{j} \quad \mathcal{M}_{i}\left[A_{j}(t)\right] \quad \tilde{O}_{j}\right) \mathrm{d}_{i+k}[x]=\mathrm{d}_{i}[f(t)],
$$

where $\mathbf{A}=\left(\begin{array}{llll}A_{k} & A_{k-1} & \ldots & A_{0}\end{array}\right), D_{i}[\mathbf{A}(t)]$ is a $[(i+1) n \times(i+k+1) n]$-matrix, $O_{j}, \tilde{O}_{j}$ are zero blocks of dimension $[(i+1) n \times j n]$ and $[(i+1) n \times(k-j) n], j=\overline{0, k}$, correspondingly. In what follows, we will use splitting

$$
D_{i}[\mathbf{A}(t)]=\left(\tilde{B}_{i}(t) \quad \Gamma_{i}[\mathbf{A}(t)]\right)
$$

where $\Gamma_{i}[\mathbf{A}(t)]$ is a block-triangular matrix with $A_{k}(t)$ standing on the diagonal.

The concept of index is quite complex and can be approached in several ways (see, for example, monographs [6-8] and references listed there). Here we employ the definition that was introduced in [13] for index one DAEs and modify it for DAE (5).

Definition 5. Assume that set of solutions $\mathcal{X}=\left\{x \equiv x(t): \Lambda_{k} x-f=0, t \in T\right\}$ to $D A E$ (5) is non-empty, and, starting with some natural number $l$, for any vector-function $x_{\varepsilon} \equiv$ $x_{\varepsilon}(t):\left\|\mathrm{d}_{l-1}\left[\Lambda_{k} x_{\varepsilon}-f\right]\right\|_{L_{2}(T)}<\varepsilon$ there exists solution $x(t) \in \mathcal{X}:\left\|x(t)-x_{\varepsilon}(t)\right\|_{L_{2}(T)} \leq \kappa \varepsilon$ where $\kappa$ is some constant. Then, we say that DAE (5) is index $l$.

The similar notion but defined in $\mathbf{C}^{i}(T)$ instead of $L_{2}(T)$ is called perturbation index $[6,8]$. Below we give some results from [12]. 
Theorem 1. Let

1) $D A E \Lambda_{k} x=f, t \in T$, be index $l$;

2) $A_{i}(t) \in \mathbf{C}^{m}(T), i=\overline{0, k}, m=\max \{(k-1) n+r+1,2 l\}, r=\mathbf{r}\left[A_{k}(t)\right]$.

Then,

1) there exists the Cauchy type solution and $\phi(t)$ from (11) has form

$$
\psi(t)=\int_{\alpha}^{t} K(t, s) f(s) d s+\sum_{j=0}^{l-k} C_{j}(t) f^{(j)}(t), l \geq k, \psi(t)=\int_{\alpha}^{t} K(t, s) f(s) d s, l<k,
$$

where $K(t, s), C_{j}(t)$ are some $(n \times n)$-matrices, $t \in T,(t, s) \in T \times T$;

2) if $\mu=0$ and $l \leq k, \mathcal{K}(t, s) \in \mathbf{C}^{l}(T \times T)$, system (6) is solvable for any $\lambda$ and its general solution has form

$$
z(t, c)=Y_{d}(t) c+g(t), t \in T,
$$

where $Y_{d}(t)=\left(E_{n}+\lambda \mathbf{V}\right) X_{d}(t), g(t)=\left(E_{n}+\lambda \mathbf{V}\right) \psi(t), \mathbf{V}$ is some Voletrra operator, $E_{n}$ is n-dimensional identity matrix;

3) if homogeneous DAE (5) has only zero solution $(d=0)$, then

$$
x(t)=\psi(t)=\left(\begin{array}{llll}
E_{n} & 0 & \ldots & 0
\end{array}\right) D_{l-k}^{+}[\mathbf{A}(t)] \mathrm{d}_{l-k}[f(t)]=\sum_{j=0}^{l-k} C_{j}(t) f^{(j)}(t) ;
$$

4) starting with $i=l$, the following equalities hold

$$
\operatorname{rank} \Gamma_{i}[\mathbf{A}(t)]=\text { const, } \Gamma_{i}^{+}[\mathbf{A}(t)] \Gamma_{i}[\mathbf{A}(t)]=\left(\begin{array}{cc}
E_{n} & 0 \\
0 & Z_{22}(t)
\end{array}\right), t \in T,
$$

where $Z_{22}(t)$ is some block of the appropriate dimension, and first $n$ rows of matrix $\Gamma_{l}^{+}[\mathbf{A}(t)]$, split into $(n \times n)$-blocks, can be taken as LRO coefficients.

Lemma 1. Let

1) the Cauchy type solution $x(t, c) \in \mathbf{C}^{m_{1}}(T)$ to the $D A E(5)$ be defined on $T$;

2) $A_{k}(t), A_{k-1}(t), \ldots, A_{0}(t) \in \mathbf{C}^{m_{2}}(T)$, where $m_{1}=(k-1) n+r+2, m_{2}=2((k-$ 1) $n+r)+3$. Then, DAE (5) has an LRO on T.

Below we prove the following statement.

Theorem 2. Let

1) system (5) satisfy Theorem 1 ;

2) $\lambda=0$ and $\mathrm{K}(t, s) \in \mathbf{C}^{l}(T \times T)$ in (6).

Then, (6) is solvable for all $\mu$, except maybe countable set $\left\{\mu_{i}, i=0,1,2, \cdots\right\}$, and its general solution with $\mu \neq \mu_{i}$ has the form

$$
z(t, c)=Z_{d}(t) c+\phi(t), t \in T
$$

where $Z_{d}(t)=\left(E_{n}+\mu \mathbf{W}\right) X_{d}(t), \phi(t)=\left(E_{n}+\mu \mathbf{W}\right) \psi(t), \mathbf{W}$ is a Fredholm operator. 
Proof. Rewrite (6) for $\lambda=0: \Lambda_{k} z=-\mu \Phi z+f: \sum_{i=0}^{k} A_{i}(t) z^{(i)}(t)=w(t), t \in T$, where $w(t)=-\mu \int_{\alpha}^{\beta} \mathrm{K}(t, s) z(s) d s+f(t)$. Using (14) and (11), write down the expression:

$$
z(t, c)=X_{d}(t) c+\int_{\alpha}^{t} K(t, s) w(s) d s+\sum_{j=0}^{l-k} C_{j}(t) w^{(j)}(t), t \in T .
$$

Due to the fact that the product of the Volterra and Fredholm operators is a Fredholm operator, we obtain a system of second kind Fredholm equations

$$
z(t)=\mu \int_{\alpha}^{\beta} W(t, s) z(s) d s+\nu(t)
$$

where

$$
\begin{gathered}
\int_{\alpha}^{\beta} W(t, s) z(s) d s=\int_{\alpha}^{t}\left[K(t, s) \int_{\alpha}^{\beta} \mathrm{K}(s, \tau) z(\tau) d \tau\right] d s+\sum_{j=0}^{l-k} \int_{\alpha}^{\beta} C_{j}(t)\left[\partial^{j} \mathrm{~K}(t, s) / \partial t^{j}\right] z(s) d s \\
\nu(t)=X_{d}(t) c+\int_{\alpha}^{t} K(t, s) f(s) d s+\sum_{j=0}^{k-1} C_{j}(t) f^{(j)}(t) .
\end{gathered}
$$

For system (18), except maybe countable set $\left\{\mu_{i}, i=0,1,2, \cdots\right\}$, we can use the known inversion formula [14]:

$$
z(t)=\left(E_{n}+\mu \mathbf{W}\right) \nu(t)=\nu(t)+\mu \int_{\alpha}^{\beta} \tilde{W}(t, s, \mu) \nu(s) d s,
$$

where $\tilde{W}(t, s, \mu)$ is the resolvent kernel for (18). The validity of the statement follow from (19).

Corollary 1. Let

1) Theorem 1 be satisfied;

2) $\lambda, \mu \neq 0, l \leq k$ and $\mathcal{K}(t, s), \mathrm{K}(t, s) \in \mathbf{C}^{l}(T \times T)$ in (6).

Then, (6) is solvable for all $\mu$, except maybe a countable set $\left\{\mu_{i}, i=0,1,2, \cdots\right\}$, its general solution has the following form for $\mu \neq \mu_{i}$ :

$$
z(t, c)=\tilde{Z}_{d}(t) c+\tilde{\phi}(t), t \in T
$$

where $\tilde{Z}_{d}(t)=\left(E_{n}+\mu \tilde{\mathbf{W}}\right) X_{d}(t), \tilde{\phi}(t)=\left(E_{n}+\mu \tilde{\mathbf{W}}\right) \psi(t), \tilde{\mathbf{W}}$ is some Fredholm operator.

Lemma 2. Let Theorem 1, Theorem 2 and Corollary 1 be satisfied. Then, initial problems (5), (6), (8), have solution $x(t), y(t), z(t) \in \mathbf{C}^{k}(T)$, if and only if systems

$\mathrm{d}_{k-1}\left[X_{d}(\alpha)\right] c=\mathrm{d}_{k-1}[\psi(t)]-\bar{a}, \mathrm{~d}_{k-1}\left[Z_{d}(\alpha)\right] c=\mathrm{d}_{k-1}[\phi(t)]-\bar{b}, \mathrm{~d}_{k-1}\left[\tilde{Z}_{d}(\alpha)\right] c=\mathrm{d}_{k-1}[\tilde{\phi}(t)]-\bar{b}$ 
are solvable with respect to $c$, these solutions are unique, if the matrices that multiply $c$ have full rank. Here $\bar{b}=\left(\begin{array}{llll}b_{1}^{\top} & b_{2}^{\top} & \ldots & b_{k-1}^{\top}\end{array}\right)^{\top}$.

It is well-known that in practice we usually address not with ideal problem (6), (8), but its perturbed version:

$$
\begin{gathered}
\left(\Lambda_{k}+\lambda V+\mu \Phi\right) \tilde{z}=\tilde{f}, t \in T, \\
\tilde{z}^{(j)}(\alpha)=\tilde{b}_{j}, j=\overline{0, k-1},
\end{gathered}
$$

where $\tilde{b}_{j}$ are the given vectors from $\mathbf{R}^{n}$.

Theorem 3. Let

1) Corollary 1 be satisfied;

2) problems (6), (8), and (21), (22) satisfy Lemma 2.

Then, the following estimates hold

$$
\|\mathrm{v}(t)\|_{\mathbf{C}(T)} \leq \kappa_{2}\|\mathrm{c}\|_{I}+\kappa_{3}\|\varphi(t)\|_{\mathbf{C}(T)},\|\mathrm{v}(t)\|_{L_{2}(T)}^{2} \leq \tilde{\kappa}_{2}\|\mathrm{c}\|_{E}^{2}+\tilde{\kappa}_{3}\|\varphi(t)\|_{L_{2}(T)}^{2}
$$

where $\left.\mathrm{v}(t)=z(t)-\tilde{z}(t), \mathrm{c}=\left(\begin{array}{lll}{\left[\tilde{b}_{0}-b_{0}\right.} & ]^{\top} \quad\left[\begin{array}{lll}\tilde{b}_{1}-b_{1}\end{array}\right]^{\top} \quad \ldots \quad\left[\tilde{b}_{k-1}-b_{k-1}\right.\end{array}\right]^{\top}\right)^{\top}, \varphi(t)=f(t)-$ $\tilde{f}(t), \kappa_{j}, \tilde{\kappa}_{j}$ are some positive constants, $j=2,3$.

Proof. Using (6), (8), (21), (22), we can write down the following initial problem

$$
\left(\Lambda_{k}+\lambda V+\mu \Phi\right) \mathrm{v}=\varphi(t), t \in T, \mathrm{v}^{(j)}(\alpha)=b_{j}-\tilde{b}_{j}, j=\overline{0, k-1},
$$

where $\mathrm{v} \equiv y(t)=z(t)-\tilde{z}(t)$. By integrating the system from (24) $k$ times, we obtain the system of integral equations

$$
\left(A_{k}+\Theta+\lambda \tilde{V}+\mu \tilde{\Phi}\right) \mathrm{v}=h(t)+\sum_{j=0}^{k-1}(t-\alpha)^{j} c_{j}, t \in T
$$

where

$$
\begin{gathered}
\left.A_{k}=A_{k}(t), \tilde{V} \mathrm{v}=\int_{\alpha}^{t} \varpi_{k-1}(t-\sigma)^{k-1}\left[\int_{\alpha}^{\sigma} \mathcal{K}(\sigma, s) \mathrm{v}(s) d s\right] d \sigma\right] \\
\left.\Theta \mathrm{v}=\int_{\alpha}^{t} \mathcal{Q}(t, s) \mathrm{v}(s) d s, \tilde{\Phi} \mathrm{v}=\int_{\alpha}^{t} \varpi_{k-1}(t-\sigma)^{k-1}\left[\int_{\alpha}^{\beta} \mathrm{K}(\sigma, s) \mathrm{v}(s) d s\right] d \sigma\right], \\
\mathcal{Q}(t, s)=\sum_{j=0}^{k-1} \varpi_{j-1}(t-s)^{j} W_{j}(s), h(t)=\int_{\alpha}^{t} \varpi_{k-1}(t-s)^{k-1} \varphi(s) d s, s \in T,
\end{gathered}
$$

$W_{j}(s)$ are linear combinations of matrices $A_{k}(t), A_{k-1}(t), \ldots, A_{0}(t)$ and their $k$ derivaties, $c_{j}$ are constant vectors in the form the linear combinations of initial data $\mathrm{v}^{j}(\alpha), j=$ $\overline{0, k-1}, \varpi_{j}=1 / j !, j \geq 1$. For example, if $k=2$, then $W_{0}(s)=A_{1}(s)-2 A_{2}^{(1)}(s), W_{1}(s)=$ $A_{0}(s)-A_{1}^{(1)}(s)+A_{2}^{(2)}(s), c_{0}=A_{2}(\alpha) \mathrm{v}(\alpha), c_{1}=A_{2}(\alpha) \mathrm{v}^{(1)}(\alpha)+\left[A_{1}(\alpha)-A_{2}^{(1)}(\alpha)\right] \mathrm{v}(\alpha)$. Substitute $\xi_{j}-\tilde{\xi}_{j}$ into $(25)$ instead of $\mathrm{v}^{(j)}(\alpha)$. We get

$$
\left(A_{k}+\Theta+\lambda \tilde{V}+\mu \tilde{\Phi}\right) \mathrm{v}=h(t)+\mathcal{H}(t) \mathrm{c}, t \in T,
$$


where $\mathcal{H}(t)$ is $(n \times k n)$-matrix with the polynomial elements depending on $t$. The solution to (26) coincides with the solution to initial problem (24). Since the operations of differentiation and integration are interchangeable, there exists operator $\tilde{\Omega}_{l}=$ $\sum_{j=0}^{l} \tilde{L}_{j}(t)(d / d)^{j}, l \leq k$, where $\tilde{L}_{j}(t)$ are $(n \times n)$-matrices from $\mathbf{C}(T)$, with the property

$$
\begin{gathered}
\tilde{\Omega}_{l}\left[\left(A_{k}+\Theta+\lambda \tilde{V}+\mu \tilde{\Phi}\right) \mathrm{v}\right]= \\
=\tilde{A}_{k}(t) \mathrm{v}(t)+\int_{0}^{t} \tilde{\mathcal{Q}}(t, s) \mathrm{v}(s) d s+\lambda \tilde{\Omega}_{l} \circ \Phi \mathrm{v}=\tilde{\Omega}_{l}[h(t)+\mathcal{H}(t) \mathrm{c}], t \in T,
\end{gathered}
$$

where $\operatorname{det} \tilde{A}_{k}(t) \neq 0 \forall t \in T$. In other words, $\tilde{\Omega}_{l}$ is a version of LRO for operator $A_{k}+\Theta$ : $\tilde{\Omega}_{l} \circ\left(A_{k}+\Theta\right)=\tilde{A}_{k}+\tilde{\Theta}$. System $(27)$ is the system of the second kind Fredholm equations with a continuous kernel and a continuous free term. According to [14], there exists the Fredholm operator $\Phi_{R}$ with a continuous kernel, such that $\mathrm{v}(t)=\left[E_{n}+\Phi_{R}\right] \tilde{\Omega}_{l}[h(t)+$ $\mathcal{H}(t) \mathrm{c}], t \in T$. Trivial estimates and computations yield inequalities (23).

We should note that if $l>k$, the solution to (24) includes the derivatives of $\varphi(t)$. Therefore, there is always exists such vector-function $\tilde{f}(t)$, that for the fixed initial data

$$
\|\varphi(t)\|_{*}<\varepsilon,\|x(t)-\tilde{x}(t)\|_{*} \rightarrow \infty, \varepsilon \rightarrow 0,
$$

where $*$ stands for one of the spaces: $L_{2}(T)$ or $\mathbf{C}(T)$.

\section{Linearizartion of Nonlinear System}

Models from applications are usually described by nonlinear DAEs and singular systems quasi-linear integral differential equations. Consider some closed $(n=\nu)$ nonlinear systems of form(3). Let there be given problem

$$
\begin{gathered}
J_{k}(u) u:=\mathrm{A}\left(u^{(k-1)}, \cdots, u^{(1)}, u, t, \mathcal{V}_{1} u, \lambda\right) u^{(k)}+\mathrm{B}\left(u^{(k-1)}, \cdots, u^{(1)}, u, t, \mathcal{V}_{2} u, \lambda\right)=0, t \in T, \\
u^{(j)}(\alpha)=a_{j}, j=\overline{0, k-1},
\end{gathered}
$$

where $\mathcal{V}_{i}, i=1,2$ are some sets of Volterra operators: $\mathcal{V}_{i}=\left\{\mathcal{V}_{i, j}, j=1,2, \cdots q_{i}\right\}$, matrix $\mathrm{A}($.$) and vector-function \mathrm{B}($.$) are defined on sets$

$$
\begin{gathered}
\mathcal{U}_{1}=\left\{\xi: g_{k-1}, \cdots, g_{1}, g_{0} \in \mathbf{R}^{n}, \gamma_{1} \in \mathbf{R}^{\tilde{n}_{1}}, t \in T, \lambda \in[\gamma, \delta] \subset \mathbf{R}^{1}\right\}, \\
\mathcal{U}_{2}=\left\{\varsigma: g_{k-1}, \cdots, g_{1}, g_{0}, \gamma_{2}, t, \lambda\right\}, \gamma_{2} \in \mathbf{R}^{\tilde{n}_{2}},
\end{gathered}
$$

$\mathcal{V}_{i}: \varpi=\left(t, s, g_{0}\right) \in T \times T \times \mathbf{R}^{n}$. It is assumed that entries of (28) are sufficiently smooth. There exist several approaches to the study of nonlinear DAEs. They are based on the analysis of the matrix pencils structures, extended systems and application of the techiniques from algebraic geometry (see, for example, $[6-8,15,17,18]$ ).

Definition 6. The combination of (28) and its derivatives up to order $i: \mathrm{d}_{i}\left[J_{k}(u) u\right]=$ $0, t \in T$, where $\mathrm{d}_{i}[$.$] is operator from (9), is said to be the i$-extended system (28). 
Definition 7. Let there exist operator

$$
\Omega_{l}(v):=\sum_{j=0}^{l} L_{j}\left(t, v, v^{(1)}, \cdots, v^{(m)}, \mathcal{V}_{3} v, \lambda\right)(d / d)^{j}
$$

where $L_{j}\left(\xi_{1}\right)$ are some $(n \times n)$ smooth matrices from the domain, $\mathcal{V}_{3}$ is a set of Volterra operators, $\xi_{1}=\left(t, g_{0}, \cdots, g_{1}, g_{m}, \gamma_{3}, \lambda\right)$, with property

$$
\begin{gathered}
\Omega_{l}(v) \circ J_{k}(v) v=\tilde{\mathrm{A}}\left(v^{(k-1)}, \cdots, v^{(1)}, v, t, \tilde{\mathcal{V}}_{1} v, \lambda\right) u^{(k)}+ \\
+\tilde{\mathrm{B}}\left(v^{(k-1)}, \cdots, v^{(1)}, v, t, \tilde{\mathcal{V}}_{2} v, \lambda\right) \forall v=v(t, \lambda) \in \mathbf{C}^{\max \{l, m\}+k, 0}(T \times[\gamma, \delta]),
\end{gathered}
$$

where $\tilde{\mathrm{A}}(\tilde{\xi})$ is $(n \times n)$-matrix, $\tilde{\mathrm{B}}(\varsigma)$ is some vector-function, both continuous in the domain, $\tilde{\xi}=\left(g_{k-1}, \cdots, g_{1}, g_{0}, \tilde{\gamma}_{1}, t, \lambda\right), \tilde{\varsigma}=\left(g_{k-1}, \cdots, g_{1}, g_{0}, \tilde{\gamma}_{2}, t, \lambda\right), \tilde{\mathcal{V}}_{i}$ are some sets of Volterra operators in initial point $\bar{\xi}=\left(a_{k-1}, \cdots, a_{1}, a_{0}, 0, \alpha, \bar{\lambda}\right)$,

$$
\operatorname{det} \tilde{\mathrm{A}}(\bar{\xi}) \neq 0 \text {. }
$$

Then, operator $\Omega_{l}(v)$ is said to be the left regularizing operator (LRO) for the system (29). The smallest possible integer number $\max \{l, m\}$ is said to be index of (29).

Example 1. Let there be given two systems

$$
\begin{gathered}
J_{1}(u) u=\left(\begin{array}{cc}
u_{2} \sin \left(\mathcal{V}_{1} u\right) & 0 \\
0 & 0
\end{array}\right)\left(\begin{array}{l}
\dot{u}_{1} \\
\dot{u}_{2}
\end{array}\right)+\left(\begin{array}{c}
u_{1}+e^{\mathcal{V}_{2} u}-1 \\
u_{2}
\end{array}\right)=0, u=\left(\begin{array}{l}
u_{1} \\
u_{2}
\end{array}\right), \\
\hat{J}_{1}(u) u=\left(\begin{array}{cc}
0 & u_{2} \\
0 & 0
\end{array}\right)\left(\begin{array}{l}
\dot{u}_{1} \\
\dot{u}_{2}
\end{array}\right)+\left(\begin{array}{l}
u_{1} \\
u_{2}
\end{array}\right)=0, t \in T
\end{gathered}
$$

where $\mathcal{V}_{1} u=\int_{\alpha}^{t}\left(\begin{array}{ll}1 & 0\end{array}\right) u(s) d s, \mathcal{V}_{2} u=\int_{\alpha}^{t}\left(\begin{array}{ll}0 & 1\end{array}\right) u(s) d s$. It is easy to verify that systems $(30)$, (31) have only a zero solution on an arbitrary subset $T \subset \mathbf{R}^{1}$. Trivial computations show that quasi-linear operators

$$
\begin{gathered}
\Omega_{1}(u)=\left(\begin{array}{cc}
0 & -\cos \left(\mathcal{V}_{1} u\right) u_{2} \dot{u}_{1}-\sin \left(\mathcal{V}_{1} u\right) \ddot{u}_{1} \\
0 & 0
\end{array}\right)+\left(\begin{array}{cc}
1 & -\sin \left(\mathcal{V}_{1} u\right) \dot{u}_{1} \\
0 & 1
\end{array}\right) \frac{d}{d t}, \\
\hat{\Omega}_{1}(u)=\left(\begin{array}{cc}
0 & -\ddot{u}_{2} \\
0 & 0
\end{array}\right)+\left(\begin{array}{cc}
1 & -\dot{u}_{2} \\
0 & 1
\end{array}\right) \frac{d}{d t}
\end{gathered}
$$

are the LROs for the systems (30), (31), respectively, and

$$
\begin{aligned}
& \Omega_{1}(u)_{1} \circ J_{1}(u) u=\left(\begin{array}{c}
\dot{u}_{1}+u_{2} \mathcal{V}_{2} u e^{\mathcal{V}_{2} u} \\
\dot{u}_{2}
\end{array}\right), \\
& \hat{\Omega}_{1}(u)_{1} \circ \hat{J}_{1}(u) u=\left(\begin{array}{c}
\dot{u}_{1} \\
\dot{u}_{2}
\end{array}\right) \forall u \in \mathbf{C}^{2}(T) .
\end{aligned}
$$

Therefore, according to Definition 7, systems (30), (31) have index 2.

It is worth noting that it is common to differentiate algebraic relations when solving applied problems. Id we do that to (30), we obtain a system with a matrix 
$\operatorname{diag}\left\{u_{2} \sin \left(\mathcal{V}_{1} u\right), 1\right\}$ singular at initial point $u(\alpha)=0$. However, we can build an LRO for (31). Here

$$
\hat{\Omega}_{2}(u)=\left(\begin{array}{cc}
\frac{d}{d t} & 0 \\
0 & 1
\end{array}\right)\left(\begin{array}{cc}
1 & -u_{2} \\
0 & 1
\end{array}\right)\left(\begin{array}{cc}
1 & 0 \\
0 & \frac{d}{d t}
\end{array}\right)=\left(\begin{array}{cc}
0 & -\dot{u}_{2} \\
0 & 1
\end{array}\right) \frac{d}{d t}+\left(\begin{array}{cc}
0 & -u_{2} \\
0 & 0
\end{array}\right)\left(\frac{d}{d t}\right)^{2} .
$$

Define the following neighbourhoods:

$$
\begin{gathered}
\mathcal{Z}_{1}=\left\{\xi:\|\xi-\bar{\xi}\| \leq \rho_{1}\right\}, \\
\mathcal{Z}_{2}=\left\{\varsigma:\|\varsigma-\bar{\varsigma}\| \leq \rho_{1}\right\}, \\
\mathcal{Z}_{3}=\left\{\varpi:\|\varpi-\bar{\varpi}\| \leq \rho_{2}\right\},
\end{gathered}
$$

where $\bar{\xi}=\left(a_{k-1}, \cdots, \bar{a}_{1}, \bar{a}_{0}, 0, \alpha, \bar{\lambda}\right), \bar{\varsigma}=\left(a_{k-1}, \cdots, \bar{a}_{1}, \bar{a}_{0}, 0, \alpha, \bar{\lambda}\right), \bar{\varpi}=\left(\alpha, \alpha, a_{0}\right)$ are the initial points.

Theorem 4. Let the following conditions be satisfied:

1. $\mathrm{A}(\xi) \in \mathbf{C}^{m+1}\left(\mathcal{Z}_{1}\right), \mathrm{B}(\bar{\varsigma}) \in \mathbf{C}^{m+1}\left(\mathcal{Z}_{2}\right)$, the kernels of the operators $\mathcal{V}_{1}, \mathcal{V}_{2}$ belong to the class $\mathbf{C}^{m}\left(\mathcal{Z}_{3}\right), m \geq 1$;

2. $\operatorname{rank} \mathrm{A}(\bar{\xi})=\max \left\{\operatorname{rank} \mathrm{A}(\xi), \xi \in \mathcal{Z}_{1}\right\}$;

3. $\operatorname{rank} \mathrm{A}(\bar{\xi})=\operatorname{rank}(\mathrm{A}(\bar{\xi}) \mid-\mathrm{B}(\bar{\varsigma}))$ : initial data (29) should be chosen so that linear system $\mathrm{A}(\bar{\xi}) y=-\mathrm{B}(\bar{\varsigma})$ would fulfill the Kronecker-Capelli criterion;

4. $\operatorname{rank} \mathrm{A}(\bar{\xi})=\operatorname{deg} \operatorname{det}[\lambda \mathrm{A}(\bar{\xi})+\mathcal{B}][17]$, where

$$
\mathcal{B}=\mathcal{C}(\bar{\xi}, \bar{\varsigma}), \mathcal{C}(\xi, \varsigma)=\frac{\partial}{\partial g_{k-1}}[\mathrm{~B}(\varsigma)+\mathrm{A}(\xi) y], y=-\mathrm{A}^{+}(\bar{\xi}) \mathrm{B}(\bar{\varsigma}) .
$$

Then, there exists segment $T_{0}=[\alpha, \alpha+\varepsilon] \subseteq T, \varepsilon>0$, with a unique solution to (28), (29) $u \equiv u(t, \bar{\lambda}) \in \mathbf{C}^{m}\left(T_{0}\right)$.

The proof is based on the switching to a first order system by the change of variables and application of corresponding theorem from [19].

Theorem 5. Let problem

$$
\mathrm{A}(t) \dot{u}+\mathrm{B}\left(u, \mathcal{V}_{2} u, t\right)=0, u(\alpha)=a_{0}, t \in T,
$$

satisfy Theorem 4. Consider iterative process

$$
\mathrm{A}(t) \dot{u}_{j+1}(t)+\mathrm{C}_{\theta}(t) u_{j+1}(t)+\int_{\alpha}^{t} Q_{\theta}(t, s) u_{j+1}(s) d s=G\left(t, u_{j}(t)\right), t \in T_{0}, u_{j+1}(\alpha)=a_{0}
$$

where $j=0,1,2, \cdots, G\left(t, u_{j}(t)\right)=-\mathrm{B}\left(u_{j}(t), \mathcal{V}_{2} u_{j}, t\right)+\mathrm{C}_{\theta}(t) u_{j}(t)+\int_{\alpha}^{t} Q_{\theta}(t, s) u_{j}(s) d s$

$$
\mathrm{C}_{\theta}(t)=C\left(\theta(t), \mathcal{V}_{2} \theta, t\right), C(\varsigma)=\frac{\partial}{\partial g_{0}} \mathrm{~B}(\varsigma), Q_{\theta}(t, s)=\tilde{C}\left(\theta(t), \mathcal{V}_{2} \theta, t\right) \tilde{K}_{2, \theta}(t, s)
$$




$$
\tilde{C}(\varsigma)=\frac{\partial}{\partial \gamma_{2}} \mathrm{~B}(\varsigma), \tilde{K}_{2, \theta}(t, s)=\mathbf{K}(t, s, \theta(t)), \mathbf{K}\left(t, s, g_{0}\right)=\frac{\partial}{\partial g_{0}} K_{2}\left(t, s, g_{0}\right),
$$

$K_{2}\left(t, s, g_{0}\right)$ is the kernel of operator $\mathcal{V}_{2}, \theta(t)$ is some smooth vector-function $\mathbf{C}^{1}\left(T_{0}\right), \theta(\alpha)=$ $a_{0}$, for a sufficiently small value of $\varrho=\left\|\theta(t)-u_{*}(t)\right\|_{\mathbf{C}\left(T_{0}\right)}, u_{*}(t)$ is a solution to (32). The iterative process (33) fulfill estimate

$$
\left\|u_{j}(t)-u_{*}(t)\right\|_{\mathbf{C}\left(T_{0}\right)} \leq \mathrm{c} \cdot \kappa^{j}, \mathrm{c}=\mathrm{const}, \kappa=\text { const }<1 .
$$

Proof. Iterative process (33) was obtained by linearizing (32) at point $\theta(t)$. Matrix pencil $\lambda \mathrm{A}(t)+\mathrm{C}_{\theta}(t)$ satisfies the rank-degree criterion on $T_{0}$ and the corresponding DAE has index 1 [7]. Equation (33) satisfies Theorem 1. Initial vector $a_{0}$ satisfies the Kronecker-Capelli criterion for any $j$, whence it follows that (33) is solvable on $T_{0}$. Trivial computations and estimates with the use of (23) justify relation $z_{j+1} \leq \kappa_{1}\left\|G\left(t, u_{j}(t)\right)-G\left(t, u_{*}(t)\right)\right\|_{\mathbf{C}\left(T_{0}\right)} \leq$ $\kappa_{1} z_{j}, z_{j}(t)=u_{j}(t)-u_{*}(t), \kappa_{1}<1$, for a sufficient small value of parameter $\varrho=\| \theta(t)-$ $u_{*}(t) \|_{\mathbf{C}\left(T_{0}\right)}($ see $[7])$.

\section{Mathematical Models Based on the DAEs Perturbed by Integral Operators}

As was mentioned above, DAEs are widely used in mathematical modelling of various dynamic processes [1-8]. We focus our research on the models for hydraulic circuits. A hydraulic circuit is a system comprising an interconnected set of discrete components that transport liquid. There are four types of hydraulic-circuit diagrams: block, cutaway, pictorial and graphical. Block diagrams show the components of a circuit as blocks joined by lines, which indicate connections and/or interactions, and can be interpreted as an oriented graph. The liquid movement is directed by the following rule

$$
\bar{A} X=\bar{Q}, \bar{A}^{\top} \bar{P}=Y,
$$

where $\bar{A}$ is an $(m \times n)$ adjacency matrix, which elements take values $0,1,-1, X=$ $\left(x_{1}, x_{2}, \ldots, x_{n}\right)$ is the flow rate vectors for circuit branches, $\bar{Q}=\left(q_{1}, q_{2}, \ldots, q_{m}\right)$ is the vector of inflows in the circuit nodes. The vector of pressures $\bar{P}$ is split into the subvectors: $P=\left(p_{1}, p_{2}, \ldots, p_{l}\right)$ and $P_{m}^{*}=\left(p_{l+1}^{*}, p_{l+2}^{*}, \ldots, p_{m}^{*}\right)$ with the desired and known pressures, correspondingly. In matrix $\bar{A}^{\top}$ the columns correspond to the splitting of the vector $\bar{P}$. Vector $Y=\left(y_{1}, y_{2}, \ldots, y_{n}\right)$ denotes heads (the pressure differences at the opposite of the branch with the corresponding number). Equations (35) are nothing else but the first and second Kirchhoff laws. Due to the first law, we have $\sum_{j=0}^{m} q_{j}=0$.

Now make matrix $A$ by omitting the last $m-r$ rows from $\bar{A}$ and do the same with the last $m-r$ elements of vector $\bar{Q}$ to obtain $Q$. Write down the new system

$$
A X=Q, A^{T} P+A_{1}^{T} P_{m}^{*}=Y,\left(A^{T} A_{1}^{T}\right)=\bar{A}^{T} .
$$

Matrix $A$ is full rank: rank $A=r$. In additional to the Kirchoff laws, we assume that the flow rates on branch $v \in[1,2, \cdots, n]$ are directed by the rule, which follows from Darcy's law [16]:

$$
h_{v}+y_{v}=h_{v}+\left(p_{i(v)}-p_{j(v)}\right)=s_{v}\left(p_{i(v)}, p_{j(v)}, x_{v}\right) x_{v}\left|x_{v}\right|,
$$


where $i(v), j(v)$ are node numbers, $h_{v} \in\left(h_{1}, v_{2}, \cdots, h_{n}\right)^{\top}=H$ are hydraulic heads at branches, $s_{v}\left(p_{i(v)}, p_{j(v)}, x_{v}\right)$ are positive resistance function (below we assume that they are constant: $s_{v}=$ const). In other words, the fluid moves from the node with a bigger pressure to the node with a smaller pressure and the resistance functions are bounded for any values of arguments.

Note that (37) is solvable with respect to $x_{v}$ for any signs of $h_{v}+y_{v}$. However, sometimes it is assumed that the pressure drops are described the by formula [16]

$$
y_{v}=p_{i(v)}-p_{j(v)}=\int_{0}^{\mathrm{L}_{v}} b_{v}\left(s, x_{v}(s), p_{v}(s)\right) d s
$$

where $\mathrm{L}_{v}$ is the length of the corresponding line, $b_{v}\left(s, x_{v}(s), p_{v}(s)\right)$ are some functions derived from Darcy's laws and resistance functions. Taking into account the integration of the general motion equations with respect to the special variable, we can move from equations (37), (38) to time-dependent equations

$$
\begin{gathered}
h_{v}+y_{v}=\varrho_{v} \dot{x}_{v}(t)+s_{0, v} x_{v}(t)+\left[s_{1, v}+\kappa_{v} \int_{\alpha}^{t}\left(\theta_{v}-x_{v}(s)\right) d s\right] x_{v}(t)\left|x_{v}(t)\right|, \\
h_{v}+y_{v}=\varrho_{v} \dot{x}_{v}(t)+s_{0, v} x_{v}(t)+\int_{0}^{\mathrm{L}_{v}} \tilde{b}_{v}\left(t, s, x_{v}(s), p_{v}(s)\right) d s,
\end{gathered}
$$

where $\varrho_{v}, s_{0, v}, s_{0, v}$ are the parameters that define the process inertia and resistances (the laminar and turbulent flow components), $\theta_{v}$ are the values of the automatic regulators, $\kappa_{v}$ are the regulators amplification coefficients, $\tilde{b}_{v}\left(t, s, x_{v}(s), p_{v}(s)\right)$ are some functions obtained by integrating $b_{v}\left(s, x_{v}(s), p_{v}(s)\right)$. Taking into account (36), (39), (40), we get DAEs with integral operators:

$$
\begin{gathered}
\Psi(X, P)= \\
=\left(\begin{array}{cc}
R & 0 \\
0 & 0
\end{array}\right)\left(\begin{array}{c}
\dot{X}(t) \\
\dot{P}(t)
\end{array}\right)+\left(\begin{array}{cc}
S_{0} & A^{\top} \\
A & 0
\end{array}\right)\left(\begin{array}{c}
X(t) \\
P(t)
\end{array}\right)+\left(\begin{array}{c}
F(t, X) \\
0
\end{array}\right)=\left(\begin{array}{c}
A_{1}^{T} P_{m}^{*}(t)+H(t) \\
Q(t)
\end{array}\right), \\
\Psi_{1}(X, P)= \\
=\left(\begin{array}{ll}
R & 0 \\
0 & 0
\end{array}\right)\left(\begin{array}{c}
\dot{X}(t) \\
\dot{P}(t)
\end{array}\right)+\left(\begin{array}{cc}
S_{0} & A^{\top} \\
A & 0
\end{array}\right)\left(\begin{array}{c}
X(t) \\
P(t)
\end{array}\right)+\left(\begin{array}{c}
B(t, X . P) \\
0
\end{array}\right)=\left(\begin{array}{c}
A_{1}^{T} P_{m}^{*}(t)+H(t) \\
Q(t)
\end{array}\right),
\end{gathered}
$$

where $t \in[\alpha, \infty), R=\operatorname{diag}\left\{\varrho_{1}, \varrho_{2}, \cdots . \varrho_{n}\right\}, S_{0}=\operatorname{diag}\left\{s_{0,1}, s_{0,2}, \cdots . s_{0, n}\right\}$,

$$
\begin{gathered}
F(t, X)=\left(\left[s_{1,1}+\kappa_{v} \int_{\alpha}^{t}\left(\theta_{1}-x_{1}(s)\right) d s\right] x_{1}(t)\left|x_{1}(t)\right|,\left[s_{1,2}+\kappa_{2} \int_{\alpha}^{t}\left(\theta_{2}-x_{2}(s)\right) d s\right] x_{2}(t)\left|x_{2}(t)\right|,\right. \\
\left.\cdots,\left[s_{1, n}+\kappa_{n} \int_{\alpha}^{t}\left(\theta_{n}-x_{n}(s)\right) d s\right] x_{n}(t)\left|x_{n}(t)\right|\right)^{\top} \\
=\left(\int_{0}^{\mathrm{L}_{1}} \tilde{b}_{1}\left(t, s, x_{1}(s), p_{1}(s)\right) d s, \int_{0}^{\mathrm{L}_{2}} \tilde{b}_{2}\left(t, s, x_{2}(s), p_{2}(s)\right) d s, \cdots, \int_{0}^{\mathrm{L}_{n}} \tilde{b}_{n}\left(t, s, x_{n}(s), p_{n}(s)\right) d s\right)^{\top} .
\end{gathered}
$$


Some properties of (40) were studied in [20]. It can be shown that (41) has index 2, at least in the neighbourhood of the initial point.

The extended model includes components of vector $P_{m}^{*}=\left(p_{l+1}^{*}, p_{l+2}^{*}, \ldots, p_{m}^{*}\right)$, which are found when solving (41) and the nonlinear system of differential equations describing mass balance and enthalpy in heat exchange units

$$
\begin{gathered}
\frac{d}{d t}\left[V_{i}(t) \rho^{\prime}\left(p_{i}^{*}(t)\right)+\left(\mathbf{V}_{i}-V_{i}(t)\right) \rho^{\prime \prime}\left(p_{i}^{*}(t)\right)\right]=x_{i, b x}(t)-x_{i, b i x}(t), \\
\frac{d}{d t}\left[V_{i}(t) \rho^{\prime}\left(p_{i}^{*}(t)\right) \iota^{\prime}\left(p_{i}^{*}(t)\right)+\left(\mathbf{V}_{i}-V_{i}(t)\right) \rho^{\prime \prime}\left(p_{i}^{*}(t)\right) \iota^{\prime \prime}\left(p_{i}^{*}(t)\right)+M_{i} c_{i} \tau^{\prime}\left(p_{i}^{*}(t)\right)\right]= \\
=x_{i, b x}(t) \iota_{i, b x}(t)-x_{i, b i x}(t) \iota^{\prime}\left(p_{i}^{*}(t)\right)-x_{i, p r}(t) \iota_{i, p r}(t),
\end{gathered}
$$

where $p_{i}^{*}(t), V_{i}(t)$ are the desired pressures and water values in heat exchange units, $x_{i, b x}(t), x_{i, b i x}(t), x_{i, p r}(t)$ are the components of $X=X(t)$ (water or steam flows entering and leaving the node $i), i \in\{l+1, l+2, \cdots, m\}, \tau^{\prime}(),. \rho^{\prime}(),. \rho^{\prime \prime}(.) \iota^{\prime}(),. \iota^{\prime \prime}($.$) are the known$ functions connecting parameters of heat exchange units, such as temperature, pressures, water and steam densitities, $\mathbf{V}_{i}, M_{i}, c_{i}$ are the given volume, mass and metal capacity of heat exchanger units, $\iota_{i, b x}, \iota_{i, p r}$ are the given enthalpy of the steam entering heat exchanger unit and the enthapy of the heated water.

If we differentiate the second block equation of (41), we obtain a new system $\tilde{\Psi}(X, P)=$ 0, (43), (44), which, for the condistent initial data, satisfies Theorem 4. Numerical experiments that employed the implicit Euler scheme showed that the mathematical model of the straight-through boiler with a turbine and a regeneration system (see the hydraulic circuit graph from [21]) has a solution and this solution tends to the stationary mode preset by regulators.

Acknowledgements. This work has been supported by the Russian Foundation for Basic Research, Grants Nos. 8-01-00643, 18-51-54001 and by the Basic Research Program of the Siberian Branch of the Russian Academy of Sciences No. AAAA-A17-117030310443-5.

\section{References}

1. Reich S. Differential-Algebraic Equations and Applications in Circuit Theory. Universität Potsdam, 1992.

2. Eich-Soellner E., Führer C. Numerical Methods in Multibody Systems. Stuttgart, Teubner, 1998. DOI: $10.1007 / 978-3-663-09828-7$

3. Balyshev O.A., Tairov E.A. Analis perehodnyh $i$ stacionarnyh processov $v$ truboprovodnyh sistemah [Analysis of Transient and Steady-State Processes in Pipeline Systems]. Novosibirsk, Nauka, 1999. (in Russian)

4. Vlach J., Singhal K. Computer Methods for Circuit Analysis and Design. N.Y., Van Nostrand Reinhold, 1983.

5. Sviridyuk G.A., Fedorov V.E. Linear Sobolev Type Equations and Degenerate Semigroups of Operators. Utrecht, Boston, Köln, Tokyo, VSP, 2003. DOI: 10.1515/9783110915501

6. Brenan K.E., Campbell S.L., Petzold L.R. Numerical Solution of Initial-Value Problems in Differential Algebraic Equations. Philadelphia, SIAM Publications, 1996.

7. Boyarintsev Yu.E., Chistyakov V.F. Algebro-differencial'nye sistemy. Metody resheniya $i$ issledovaniya [Algebraic Differential Systems. Methods for Investigation and Solution]. Novosibirsk, Nauka, 1998. (in Russian) 
8. Lamour R., Marz R., Tischendorf C. Differential-Algebraic Equations: a Projector Based Analysis. Berlin, Springer, 2013. DOI: 10.1007/978-3-642-27555-5

9. Luzin N.N. On the Study of the Matrix Theory of Differential Equations. Avtomatika $i$ Telemekhanika, 1940, no. 5, pp. 4-66. (in Russian)

10. Chistyakov V.F. Algebro-differentsial'nye operatory s konechnomernym yadrom [Algebraic Differential Operators with a Finite-Dimensional Kernel]. Novosibirsk, Nauka, 1996. (in Russian)

11. Mehrmann V., Shi C. Transformation of High Order Linear Differential-Algebraic Systems to First Order. Numerical Algorithms, 2006, no. 42, pp. 281-307. DOI: 10.1007/s11075-006$9030-\mathrm{x}$

12. Chistyakov V.F., Chistyakova E.V. Linear Differential-Algebraic Equations Perturbed by Volterra Integral Operators. Differential Equations, 2017, vol. 53, no. 10, pp. 1-14. DOI: $10.1134 /$ S0012266117100044

13. Bulatov M.V., Chistyakov V.F. A Method for Solving Linear Singular Systems of DAEs with Index Higher than One. Chislennye metody analiza i ikh prilozheniya [Numerical Analysis Methods and Their Applications], Irkutsk, 1987, pp. 100-105. (in Russian)

14. Krasnov M.L. Integral'nye uravneniya: vvedenie v teoriyu [Integral Equations: Introduction to the Theory]. Moscow, Nauka, 1975. (in Russian)

15. Pazii N.D. Local Analytical Classification of the Sobolev Type Equations. PhD Thesis. Chelyabinsk, 1999. (in Russian)

16. Merenkov A.P., Hasilev V.Ya. Teoriya gidravlicheskikh tsepey [Theory of Hydraulic Circuits]. Moscow, Nauka, 1985. (in Russian)

17. Chistyakov V.F. Linearization of Singular Systems of Quasi-Linear Ordinary Differential Equations. Priblizhennye metody resheniya operatornykh uravnenij $i$ ikh prilozheniya [Approximare Methods for Solving Operator Equations and Their Applications], Irkutsk, 1982, pp. 146-157. (in Russian)

18. Chistyakov V.F. The Connection Between the Matrix Pencil and the Existence of a Solution to an Implicit System of ODEs. Metody optimizacii $i$ issledovaniya operacij [Methods for Optimization and Operational Research], Irkutsk, 1982, pp. 194-202.

19. Chistyakova E.V., Chistyakov V.F. On the Solvability of Degenerate Systems of General Quasilinear Integro-Differential Equations. Computational Technologies, 2011, vol. 16, no. 5, pp. $100-114$.

20. Chistyakova E.V., Nguyen Duc Bang. Investigation of the Unsteady-State Hydraulic Networks by Means of Singular Systems of Integral Differential Equations. Bulletin of the South Ural State University. Series: Mathematical Modelling, Programming and Computer Software, 2016, vol. 9, no. 1, pp. 59-72. DOI: $10.14529 / \mathrm{mmp} 160105$

21. Levin A.A., Chistyakov V.F., Tairov E.A. On Application of the Structure of the Nonlinear Equations System, Describing Hydraulic Circuits of Power Plants. Bulletin of the South Ural State University. Series: Mathematical Modelling, Programming and Computer Software, 2016, vol. 9, no. 4, pp. 53-62. DOI: $10.14529 / \mathrm{mmp} 160405$

Received August 08, 2018 


\title{
ЛИНЕАРИЗАЦИЯ ДИФФЕРЕНЦИАЛЬНО-АЛГЕБРАИЧЕСКИХ УРАВНЕНИЙ С ВОЗМУЩЕНИЯМИ В ВИДЕ ИНТЕГРАЛЬНЫХ ОПЕРАТОРОВ И ПРИЛОЖЕНИЯ К МОДЕЛЯМ ТЕПЛОЭНЕРГЕТИКИ
}

\author{
Е.В. Чистякова ${ }^{1}$, В.Ф. Чистяков ${ }^{1}$, А.А. Левин ${ }^{2}$ \\ ${ }^{1}$ Институт динамики систем и теории управления им. В.М. Матросова СО РАН, \\ г. Иркутск, Российская Федерация \\ ${ }^{2}$ Институт систем энергетики им. Л.А. Мелентьева СО РАН, г. Иркутск, \\ Российская Федерация
}

\begin{abstract}
Моделирование различных естественных и технических процессов часто приводит к системам, которые включают в себя обыкновенные дифференциальные уравнения и связанные с ними алгебраические соотношения. В данной работе изучаются системы квазилинейных интегро-дифференциальных уравнений с вырожденной матрицей в области определения при производной искомой вектор-функции. Такие системы можно рассматривать как дифференциально-алгебраические уравнения, возмущенные операторами Вольтерра. Получены условия разрешимости возмущенных систем и начальных задач для них, обсуждается влияние малых возмущений входных данных на решение начальных задач. Рассмотрены варианты линеаризации таких задач на основе метода Ньютона. Обсуждаются модели из области теплоэнергетики, и как пример рассматривается гидравлическая цепь, представленная в виде набора взаимосвязанных элементов, по которым течет жидкость. Численные эксперименты на основе неявной схемы Эйлера показали, что модель прямоточного котла с турбиной и системой регенерации имеет решение, которое стягивается к стационарному режиму, заданному регуляторами.

Ключевые слова: дифференциально-алгебраические уравнения; оператор Фредгольма; оператор Вольтерра; начальная задача; условия согласования; индекс.
\end{abstract}

\section{Литература}

1. Reich, S. Differential-Algebraic Equations and Applications in Circuit Theory / S. Reich. Potsdam: Universität Potsdam, 1992.

2. Eich-Soellner, E. Numerical Methods in Multibody Systems / E. Eich-Soellner, C. Führer.Stuttgart: Teubner, 1998.

3. Балышев О.А. Анализ переходных и стационарных процессов в трубопроводных системах / О.А. Балышев, Э.А. Таиров. - Новосибирск: Наука, 1999.

4. Vlach, J. Computer Methods for Circuit Analysis and Design / J. Vlach, K. Singhal. - N.Y.: Van Nostrand Reinhold, 1983.

5. Sviridyuk, G.A. Linear Sobolev Type Equations and Degenerate Semigroups of Operators / G.A. Sviridyuk, V.E. Fedorov. - Utrecht; Boston; Köln; Tokyo: VSP, 2003.

6. Brenan, K.E. Numerical Solution of Initial-Value Problems in Differential Algebraic Equations / K.E. Brenan, S.L. Campbell, L.R. Petzold. - Philadelphia: SIAM Publications, 1996.

7. Бояринцев, Ю.Е. Алгебро-дифференциальные системы. Методы решения и исследования / Ю.Е. Бояринцев, В.Ф. Чистяков. - Новосибирск: Наука, 1998.

8. Lamour, R. Differential-Algebraic Equations: a Projector Based Analysis / R. Lamour, R. Marz, C. Tischendorf. - Berlin: Springer, 2013. 
9. Лузин, Н.Н. К изучению матричной теории дифференциальных уравнений / Н.Н. Лузин // Автоматика и телемеханика. - 1940. - № 5. - С. 3-66.

10. Чистяков, В. Ф. Алгебро-дифференциальные операторы с конечным ядром / В.Ф. Чистяков. - Новосибирск: Наука, 1996.

11. Mehrmann, V. Transformation of High Order Linear Differential-Algebraic Systems to First Order / V. Mehrmann, C. Shi // Numerical Algorithms. - 2006. - № 42. - P. 281-307.

12. Chistyakov, V.F. Linear Differential-Algebraic Equations Perturbed by Volterra Integral Operators / V.F. Chistyakov, E.V. Chistyakova // Differential Equations. - 2017. - V. 53, № 10. - P. $1-14$.

13. Булатов, М.В. Один метод численного решения линейных сингулярных систем ОДУ индекса выше единицы / М.В. Булатов, В.Ф. Чистяков // Численные методы анализа и их приложения. - Иркутск: СЭИ СО АН СССР, 1987. - С. 100-105.

14. Краснов, М.Л. Интегральные уравнения. Введение в теорию / М.Л. Краснов. - М.: Наука, 1975.

15. Пазий Н.Д. Локальная аналитическая классификация уравнений соболевского типа: дис. ... канд. физ.-мат. наук / Н.Д. Пазий. - Екатеринбург, 1999.

16. Меренков, А.П. Теория гидравлических цепей / А.П. Меренков, В.Я. Хасилев. - М.: Наука, 1985.

17. Чистяков, В.Ф. О линеаризации вырожденных систем квазилинейных обыкновенных дифференциальных уравнений / В.Ф. Чистяков // Приближенные методы решения операторных уравнений и их приложения. - Иркутск: СЭИ СО АН СССР, 1982. C. $146-157$.

18. Чистяков, В.Ф. О связи структуры пучка матриц с существованием решений неявной системы ОДУ / В.Ф. Чистяков // Методы оптимизации и исследования операций. Иркутск: СЭИ СО АН СССР, 1984. - С. 194-202.

19. Чистякова, Е.В. О разрешимости вырожденных систем квазилинейных интегродифференциальных уравнений общего вида / Е.В. Чистякова, В.Ф. Чистяков // Вычислительные технологии. - 2011. - Т. 16, № 5. - С. 100-114.

20. Chistyakova, E.V. Investigation of the Unsteady-State Hydraulic Networks by Means of Singular Systems of Integral Differential Equations / E.V. Chistyakova, Nguyen Duc Bang // Вестник ЮУрГУ. Серия: Математическое моделирование и программирование. - 2016. Т. 9, № 1. - С. 59-72.

21. Левин, А.А. Об использовании структуры системы нелинейных уравнений, описывающих гидравлические цепи энергоустановок при численных расчетах / А.А. Левин, В.Ф. Чистяков, Э.А. Таиров // Вестник ЮУрГУ. Серия: Математическое моделирование и программирование. - 2016. - Т. 9, № 4. - С. 53-62.

Елена Викторовна Чистякова, кандидат физико-математических наук, научный сотрудник, Институт динамики систем и теории управления им. В.М. Матросова СО PAH (г. Иркутск, Российская Федерация), elena.chistyakova@icc.ru.

Виктор Филимонович Чистяков, доктор физико-математических наук, главный научный сотрудник, Институт динамики систем и теории управления им. В.М. Матросова СО РАН (г. Иркутск, Российская Федерация), chist@icc.ru.

Анатолий Алексеевич Левин, кандидат технических наук, ведущий научный сотрудник, заведующий лабораторией, Институт систем энергетики им. Л.А. Мелентьева СО РАН (г. Иркутск, Российская Федерация), lirt@mail.ru.

Поступила в редакиию 8 августа 2018 г. 